\title{
A phase 0 analysis of ixazomib in patients with glioblastoma
}

\author{
JOSEPH QUILLIN ${ }^{1}$, RIKESH PATEL ${ }^{2}$, ERIC HERZBERG ${ }^{3}$, DENNY ALTON ${ }^{3}$, \\ GALINA BIKZHANOVA $^{3}$, LISA GEISLER ${ }^{3}$ and JEFFREY OLSON ${ }^{1}$ \\ ${ }^{1}$ Department of Neurosurgery; ${ }^{2}$ Winship Cancer Institute, Emory University, Atlanta, GA 30322; \\ ${ }^{3}$ Covance Laboratories, Inc., Madison, WI 53704, USA
}

Received June 5, 2020; Accepted July 8, 2020

DOI: $10.3892 / \mathrm{mco} .2020 .2114$

\begin{abstract}
Improving overall survival in recurrent glioblastoma remains a challenge, and drugs acting by unique mechanisms are urgently required. Ixazomib is an orally-administered proteasome inhibitor used in combination with lenalidomide and dexamethasone to treat patients with multiple myeloma who have received at least one prior therapy. However, ixazomib's ability to reach brain tumors has not been studied during its development. The aim of the present study (ClinicalTrials. gov, NCT02630030) was to establish and quantify ixazomib's presence in glioblastoma. The present study investigated 3 patients with recurrent glioblastoma after administration of oral ixazomib citrate (MLN 9708) at a fixed $4.0 \mathrm{mg}$ dose within a 3-hpreoperative window. A total of 2 blood samples were taken from each patient at the time of incision, tumor sampling and closure. Brain tumor samples were collected during tumor resection. These samples were then used to measure the plasma and brain tumor tissue concentration of the biologically-active form of ixazomib (MLN 2238). Patient 1 had plasma concentrations of ixazomib averaging 26.2, 21.8 and $15.3 \mathrm{ng} / \mathrm{ml}$ at incision, tumor sampling and closure, respectively. The brain tumor tissue concentration was $7.88 \mathrm{ng} / \mathrm{g}$. Patient 2 had the same interval and brain tumor tissue measurements of 19.0, 18.0 and $8.93 \mathrm{ng} / \mathrm{ml}$, and $2.03 \mathrm{ng} / \mathrm{g}$. Patient 3 had plasma concentration interval measurements of 25.6, 36.2 and $28.7 \mathrm{ng} / \mathrm{ml}$. Multiple brain tumor tissue samples were taken in patient 3 , with an average tissue ixazomib concentration of $3.37 \mathrm{ng} / \mathrm{g}$. Ixazomib was found at plasma concentrations commensurate with its previously established pharmacokinetic profile without clinically relevant drug-related adverse events. Ixazomib reaches glioblastoma tissues at measurable concentrations at the time of tumor resection, confirming target tissue delivery. This justifies the phase I study of ixazomib in recurrent glioblastoma currently in development.
\end{abstract}

Correspondence to: Dr Joseph Quillin, Department of Neurosurgery, Emory University, 1365 Clifton Road NE, Atlanta, GA 30322, USA

E-mail: joseph.quillin@emory.edu

Key words: ixazomib, proteasome inhibitor, bortezomib, glioblastoma

\section{Introduction}

Glioblastoma (GBM) is the most common primary glial malignancy (1). Despite its prevalence, and the resultant abundance of organized clinical investigation over several decades, GBM remains a challenging therapeutic entity from its initial diagnosis to its nearly inevitable recurrence. Multiple treatment modalities are under active investigation, offering limited promise to improving overall survival in this patient population (2). Drugs treating this disease through novel mechanisms are urgently needed.

Recently, proteasome inhibitors have been developed as an additional treatment option for recurrent and, given their measured success, newly diagnosed multiple myeloma. The proteasome is responsible for degrading damaged and ubiquinated proteins integral to normal cellular functioning (3). Selectively preventing cellular maintenance in relatively rapidly dividing neoplastic cells has proven an effective strategy. Bortezomib, an intravenous agent of this drug class, has been approved in the US for treatment of multiple myeloma since 2003 (4). Initial studies of bortezomib in mouse models demonstrated a lack of penetration of the blood brain barrier (5). Despite this, the effective anti-neoplastic characteristics of proteasome inhibitors were recognized, and bortezomib has since been investigated in GBM with good reported response (6-9).

Ixazomib (MLN2238) is a second generation, orally administered proteasome inhibitor. Following the trail blazed by the investigation of bortezomib, ixazomib has recently proven effective against multiple myeloma, offering the practical advantage of its oral bioavailability (10-12). In murine xenograft models of lymphoma, ixazomib was found to be a potent and reversible proteasome inhibitor. These murine xenograft model investigations explored the pharmacokinetic profiles of these two drugs and found them comparable. Additionally, ixazomib administration resulted in more tumor volume improvement compared with bortezomib (13). It was further demonstrated to have effect against human multiple myeloma cell lines with in vitro and in vivo studies (14-16). Despite its promise, ixazomib activity against glioblastoma was not tested during its development.

This phase 0 clinical trial utilized a new assay to identify and quantify ixazomib after pre-operative administration in human brain specimens during recurrent glioblastoma resection. 
The primary objective of this clinical trial was to establish whether ixazomib reached glioblastoma tissue after its preoperative oral administration. To this end, we sought to quantify brain tissue concentration of the agent. We also sought to establish blood and plasma concentrations of this orally administered agent throughout the course of tumor resection. A secondary objective was to evaluate the safety and tolerability of ixazomib after single dose administration in glioblastoma patients.

\section{Materials and methods}

Study design and sample size selection. A purposely small number of patients was chosen to assess this new assay of ixazomib in brain tumor tissue in view of the invasive steps (intracranial tumor sampling via craniotomy) necessary to obtain the samples. Specifically, it was determined that only three subjects would be enrolled in this phase 0 study to balance safety against analyzing enough tumor samples to meet the objective of the study: a yes or no answer of whether ixazomib reaches the brain tumor tissue after oral administration.

Summary of enrollment criteria and clinical management. Enrolled patients had recurrent or progressive glioblastoma for which surgical resection was indicated. The study was first approved by the Emory University Institutional Review Board (IRB00083003). The trial was explained to each patient and this was documented in their medical record. They then signed the informed consent after being given an opportunity to ask questions about its risks and benefits to them. They each had a Karnofsky performance status of $\geq 60$ (ECOG 2). We studied 3 patients with recurrent glioblastoma after administration of oral ixazomib citrate (MLN 9708) at a fixed $4.0 \mathrm{mg}$ dose within a 3-h preoperative window. The authors believed that three patients were enough to determine if measurable delivery was feasible and account for intertumor heterogeneity. To account for intratumor heterogeneity, three samples from different portions of the tumor were obtained in patient 3 . Their location was described in the operative report.

MLN2238 analysis. The method of qualification was performed under the general bioanalytic guidelines for reproducibility that are utilized internally at Covance Laboratories. This is proprietary. There is not a currently accepted standard method of qualification to compare this method against.

Blood samples were taken from each patient at time of incision, tumor sampling, and closure. Brain tumor samples were collected during tumor resection. These samples were then used to measure plasma and brain tumor tissue concentration of MLN2238, the biologically active boronic form of ixazomib.

Plasma sample preparation. Plasma samples $(200 \mu \mathrm{l})$ were aliquoted into a 96-well plate. $50.0 \mu \mathrm{l}$ of working ixazomib solution were added to wells. To each well, $50.0 \mu 1$ of $0.5 \mathrm{~N}$ hydrochloric acid was added and vortexmixed for $2 \mathrm{~min}$. $800 \mu 1$ of methyl tert-butyl ether was added to each well. Samples were vortex-mixed for $3 \mathrm{~min}$ and centrifuged for $10 \mathrm{~min}$ at $3,700 \mathrm{rpm}$. Supernatant $(600 \mu \mathrm{l})$ was then transferred to a clean 96-well plate and dried to completion under a stream of nitrogen set at $40^{\circ} \mathrm{C}$. The dried sample extracts were then reconstituted in $150 \mu \mathrm{l}$ of (25:75:0.1) acetonitrile:water:formic acid. The plate was vortex-mixed for $2 \mathrm{~min}$ prior to injection onto an equilibrated LC-MS/MS instrument.

Brain sample preparation. Brain homogenate was prepared using a $4 \mathrm{X}$ dilution of tissue into reverse osmosis water and homogenized using an Omni Inc. BeadRuptor homogenizer set at $5.0 \mathrm{~m} / \mathrm{sec}$. Working calibration standards were created by dilution of the intermediate solutions into brain homogenate at final concentrations of $0.500,1.00,5.00,25.0,50.0,100,250$, 450 and $500 \mathrm{ng} / \mathrm{g}$ in tissue.

Brain homogenate samples $(200 \mu \mathrm{l})$ were added to flexi tier glass inserts containing $50.0 \mu \mathrm{l}$ of working IS solution. To each insert, $50.0 \mu \mathrm{l}$ of $0.5 \mathrm{~N}$ hydrochloric acid was added and vortexmixed for $2 \mathrm{~min}$. Methyl tert-butyl ether (800 $\mu \mathrm{l})$ was added to each insert to quench the brain homogenate samples. Samples were vortex-mixed for $3 \mathrm{~min}$ and centrifuged for $10 \mathrm{~min}$ at $3,700 \mathrm{rpm}$. Supernatant $(500 \mu \mathrm{l})$ was then transferred to a clean 96-well plate and dried to completion under a stream of nitrogen set at $40^{\circ} \mathrm{C}$. The dried sample extracts were then reconstituted in $100 \mu 1$ of $(25: 75: 0.1)$ acetonitrile:water:formic acid. The plate was vortexmixed for 2 min prior to injection onto an equilibrated LC-MS/MS instrument.

Plasma and brain sample analysis and instrumentation. The samples were analyzed with a new and unique via liquid chromatography tandem mass spectrometry assay. This expands on a prior, and more limited assay method, described by Gupta et al (17). For this new assay a qualified curve range of $0.500-500 \mathrm{ng} / \mathrm{ml}$ for plasma and $0.500-500 \mathrm{ng} / \mathrm{g}$ for brain homogenate was utilized. To accomplish the stock standard solutions of Ixazomib and $\left[{ }^{13} \mathrm{C}_{9}\right]$-Ixazomib (IS) were prepared separately in a (55:45:0.1) mixture of acetonitrile:water:formic acid at a concentration of $0.500 \mathrm{mg} / \mathrm{ml}$ and stored at $-20^{\circ} \mathrm{C}$. Intermediate standard solutions of Ixazomib were prepared by dilution of stock solution at concentrations of 10.0,20.0, 100,500, $1,000,2,000,5,000,9,000$ and $10,000 \mathrm{ng} / \mathrm{m}$; and stored at $-20^{\circ} \mathrm{C}$. Intermediate quality control (QC) solutions were prepared by dilution of stock solution at concentrations of 30.0, 800, 4,000 and $8,000 \mathrm{ng} / \mathrm{ml}$ and stored at $-20^{\circ} \mathrm{C}$. A working IS solution was prepared from stock into (100:1) acetonitrile:formic acid at a concentration of $100 \mathrm{ng} / \mathrm{ml}$. Working calibration standards were created by dilution of the intermediate solutions into plasma at final concentrations of $0.500,1.00,5.00,25.0,50.0,100,250$, 450 and $500 \mathrm{ng} / \mathrm{ml}$. Similarly, the working QC samples were prepared at concentrations of 1.50, 40.0, 200 and $400 \mathrm{ng} / \mathrm{ml}$ in plasma. Each calibration curve point was generated by diluting $250 \mu \mathrm{l}$ of each intermediate standard HPLC analysis involved a gradient acquisition of $1.5 \mathrm{~min}$ using a $\mathrm{C} 18$ column in tandem with triple-quad mass spectrometer in $\mathrm{ESI}^{+}$mode. Additional details for the plasma and brain assay are summarized in Tables I and II.

Safety was assessed with routine postoperative laboratory, vital sign, neurologic exam, and imaging studies through the day of surgery to staple or suture removal. This data was collected and any adverse events graded and their relationship to ixazomib administration determined. 
Table I. Plasma assay summary.

\begin{tabular}{ll}
\hline Laboratory information & \multicolumn{1}{c}{ Description } \\
\hline Analyte & MLN2238 \\
Species & Human \\
Analytical matrix & $\mathrm{K}_{2}$ EDTA Plasma \\
ISTD & {$\left[{ }^{13} \mathrm{C}_{9}\right]-\mathrm{MLN} 2238$} \\
Qualified method (non-GLP) & Covance 8383722 \\
Qualified range & $0.500-500 \mathrm{ng} / \mathrm{ml}$ \\
LLOQ & $0.500 \mathrm{ng} / \mathrm{ml}$ \\
QC levels & $1.50,40.0,200$ and $400 \mathrm{ng} / \mathrm{ml}$ \\
Analytical technique/ & Liquid-liquid extraction/ \\
method & LC-MS/MS \\
of detection & \\
Sample volume & $200 \mu 1$ \\
Calibration model & Linear regression \\
Weighting factor & $1 / \mathrm{x}^{2}$ \\
R ${ }^{2}$ & 0.9885 \\
Accuracy and precision & Requirements of $\geq 75 \%$ of \\
& STDS within $\pm 25 \%( \pm 30 \%$ \\
& LLOQ) fulfilled; Requirements \\
& of $\geq 67 \%$ of QCs within $\pm 25 \%$ \\
fulfilled
\end{tabular}

LLOQ, lower limit of quantitation; LC, liquid chromatography; MS, mass spectroscopy; QC, quality control; STDS, standard solutions; ISTD, internal standard; GLP, Good Laboratory Practice.

\section{Results}

Drug concentrations found in plasma. Basic patient descriptive characteristics are reviewed in Table III. Patient 1 had plasma concentrations of ixazomib averaging 26.2,21.8, and $15.3 \mathrm{ng} / \mathrm{ml}$ at incision, tumor sampling, and closure respectively (Fig. 1).

Patient 2 had the same interval plasma concentration measurements drawn. These averaged 19.0, 18.0, and $8.93 \mathrm{ng} / \mathrm{ml}$ at incision, tumor sampling, and closure (Fig. 2).

Patient 3 had the same interval measurements of ixazomib plasma concentration drawn. These averaged 25.6, 36.2, and $28.7 \mathrm{ng} / \mathrm{ml}$ at incision, tumor sampling, and closure (Fig. 3).

The relative plasma concentrations between the 3 patients relative to the drugs preoperative administration were analyzed (Fig. 4).

Drug concentrations found in brain tissue. Patient 1 had brain tissue concentration of ixazomib of $7.88 \mathrm{ng} / \mathrm{g}$. Patient $2 \mathrm{had}$ brain tissue ixazomib concentration of $2.03 \mathrm{ng} / \mathrm{g}$.

Patient 3 had 3 separate brain tissue samples taken from different regions of the tumor to account for intratumor variability. Tissue sample no. 1 had an ixazomib concentration of $4.17 \mathrm{ng} / \mathrm{g}$. Tissue sample no. 2 had an ixazomib concentration of $2.70 \mathrm{ng} / \mathrm{g}$. Tissue sample no. $3 \mathrm{had}$ an ixazomib concentration of $3.25 \mathrm{ng} / \mathrm{g}$. The average ixazomib concentration between these 3 samples in patient 3 was $3.37 \mathrm{ng} / \mathrm{g}$ (Table IV).
Table II. Brain assay summary.

\begin{tabular}{ll} 
Laboratory information & \multicolumn{1}{c}{ Description } \\
\hline Analyte & MLN2238 \\
Species & Human \\
Analytical matrix & Brain \\
ISTD & {$\left[{ }^{13} \mathrm{C}_{9}\right]-\mathrm{MLN} 2238$} \\
Qualified method (non-GLP) & Covance 8383722 \\
Qualified range & $1.00-500 \mathrm{ng} / \mathrm{g}$ \\
LLOQ & $1.00 \mathrm{ng} / \mathrm{g}$ \\
QC levels & $3.00,40.0,200$ and $400 \mathrm{ng} / \mathrm{g}$ \\
Analytical technique/ & Liquid-liquid extraction/ \\
method of detection & LC-MS/MS \\
Sample volume & $200 \mu 1$ \\
Calibration model & Linear regression \\
Weighting factor & $1 / \mathrm{x}^{2}$ \\
$\mathrm{R}^{2}$ & 0.9618 \\
Accuracy and precision & Requirements of $\geq 75 \%$ of \\
& STDS within $\pm 30 \%$ fulfilled; \\
& Requirements of $\geq 67 \%$ of \\
& QCs within $\pm 30 \%$ fulfilled \\
Carryover & Passes acceptance criteria of \\
& $<$ LLOQ
\end{tabular}

LLOQ, lower limit of quantitation; LC, liquid chromatography; MS, mass spectroscopy; QC, quality control; STDS, standard solutions; ISTD, internal standard; GLP, Good Laboratory Practice.

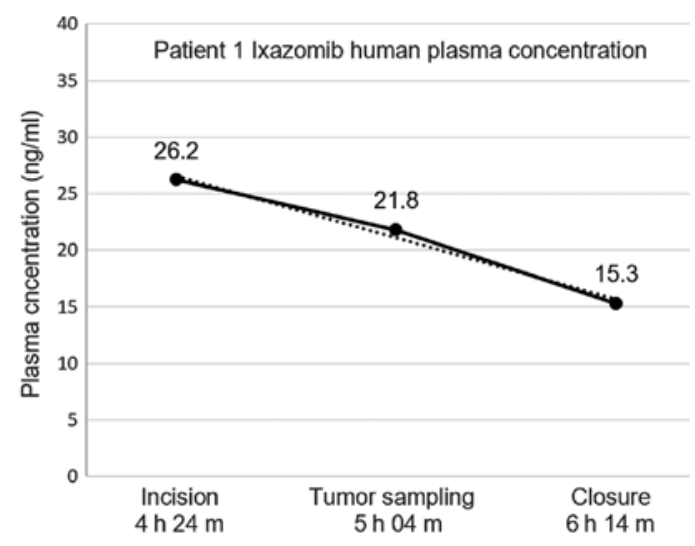

Figure 1. Average human plasma concentrations of ixazomib in Patient 1 measured relative to its preoperative oral administration. Total time after administration is noted on the $\mathrm{x}$-axis.

Adverse events reporting. We used the National Cancer Institute (NCI) Common Terminology Criteria for Adverse Events (NCI CTCAE) to stratify any adverse patient response to ixazomib. There were no clinically relevant adverse events as a result of ixazomib administration.

Patient 1 experienced grade 1 anemia, thrombocytopenia, an elevated alanine aminotransferase level, confusion and dysarthria. All of these were managed expectantly without medication administration. They also experienced grade 2 headache and nausea, which were treated with medication 
Table III. Descriptive patient information.

\begin{tabular}{lclccc}
\hline Patient & Age, years & Sex & Ethnicity & KPS & Tumor location \\
\hline 1 & 46 & Male & Black & 60 & Right frontal lobe \\
2 & 36 & Female & White & 70 & Left parietal lobe \\
3 & 69 & Male & White & 70 & Right frontal lobe
\end{tabular}

KPS, Karnofsky Performance Status.

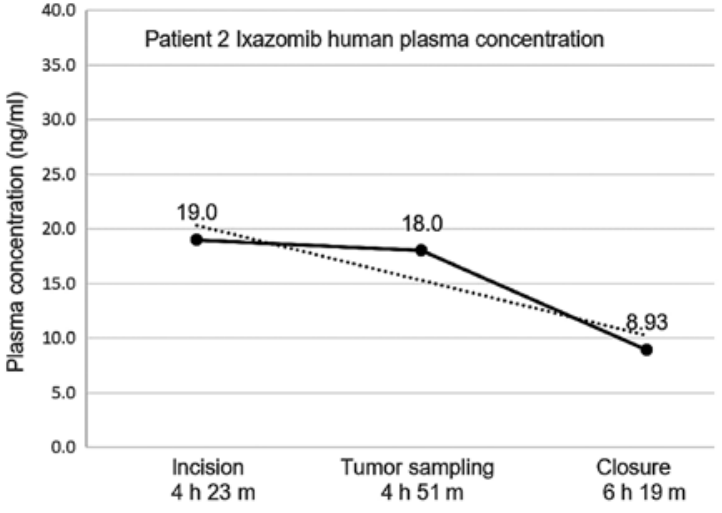

Figure 2. Average human plasma concentrations of ixazomib in Patient 2 measured relative to its preoperative oral administration. Total time after administration is noted on the $\mathrm{x}$-axis.

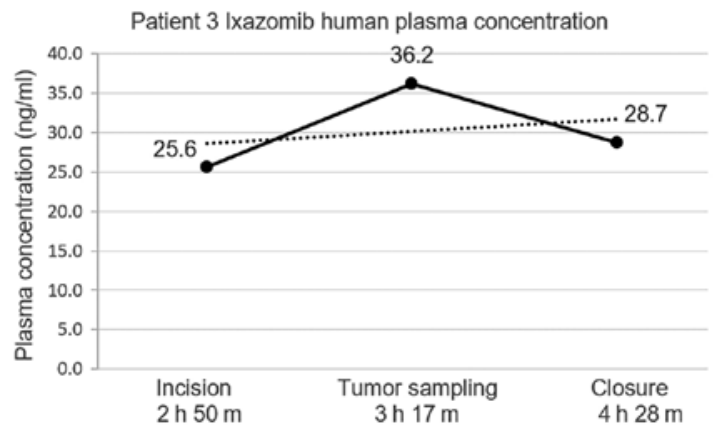

Figure 3. Average human plasma concentrations of ixazomib in Patient 3 measured relative to its preoperative oral administration. Total time after administration is noted on the $\mathrm{x}$-axis.

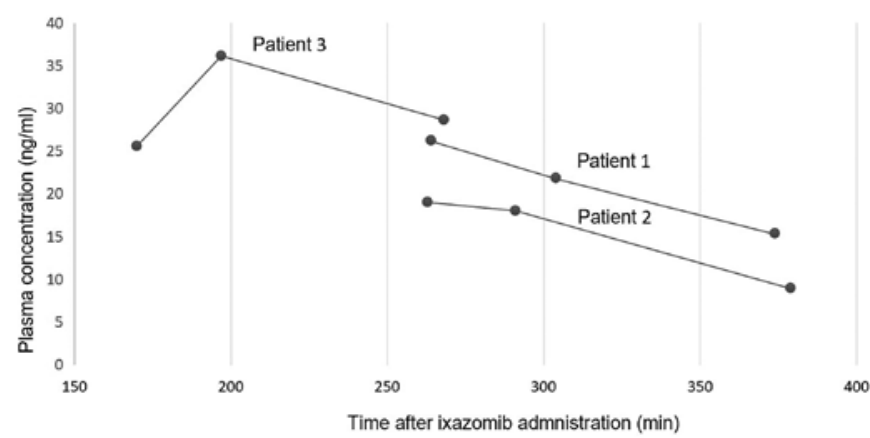

Figure 4. Average ixazomib plasma concentrations were measured in all three patients at set time points after pre-operative drug administration. This figure compares the plasma concentrations between the patients measured in min to allow comparisons to previously established ixazomib pharmacokinetic data.
Table IV. Brain tissue concentrations of ixazomib in tumor samples.

\begin{tabular}{lc} 
Patient no. & Brain tissue ixazomib concentration, $\mathrm{ng} / \mathrm{g}$ \\
\hline Patient 1 & 7.88 \\
Patient 2 & 2.03 \\
Patient 3 & 3.37 (average) \\
Tissue sample 1 & 4.17 \\
Tissue sample 2 & 2.70 \\
Tissue sample 3 & 3.25
\end{tabular}

as deemed appropriate by the evaluating physician. Patient 2 experienced grade 1 proteinuria, anemia, an elevated lipase level, confusion, and lethargy. None of these required treatment. They also experienced grade 2 oral mucosal thrush, which was treated with medication deemed appropriate by the evaluating physician. Patient 3 experienced grade 1 fatigue, early satiety, generalized weakness. None of these merited treatment. This patient also experienced grade 2 hyperthyroidism, which was treated with the appropriate medication by the evaluating physician.

\section{Discussion}

As further drug classes demonstrate their anti-neoplastic potential, it is imperative that we utilize the scientific and administrative groundwork already accomplished to evaluate their efficacy in devastating diseases such as GBM. This small phase 0 clinical trial establishes that ixazomib reaches brain tumor tissue after simple fixed dose pre-operative administration. There are measureable plasma concentrations commensurate with previously established time and dose-dependent pharmacokinetic profiles in both mice and humans with multiple myeloma. There were no serious adverse effects related to its administration. Dosing was simple. The oral administration offers the advantage of convenience in a patient population beleaguered with frequent medical office visits and medication administration. Better understanding of what comprises therapeutic drug concentrations and the extent of this efficacy on tumors will require further investigation in future clinical trials.

This clinical trial has several important limitations. Investigational drugs must be deliberately and conservatively evaluated, accentuating some of these limitations $(17,18)$. Obviously, our results are tempered by the trial's small sample size and absence of patient follow up data. Dose escalation 
studies in the future may reveal problems with safety or tolerability. While the phase I and II trials of ixazomib for multiple myeloma have been promising, there is no such guarantee with GBM. While ixazomib was present in the tumor tissue of our patients, we do not know if it could reach tumor in locations where the blood brain barrier is intact or if it can do so in a meaningful dose for tumor control. Also, normal brain samples from the three subjects were not obtained. The brain within centimeters of glioblastomas is known to be infiltrated with tumor and would not be representative of normal $(19,20)$. Taking samples of normal brain beyond those would not be feasible as surgical working space is not extended beyond that needed for the tumor surgery, and more importantly would deemed unethical in the eyes of the investigators. The blood and tissue assay used here are unique and we do not plan to submit for FDA review until more patient data is obtained and there are plans to use it as a standard diagnostic test.

Additionally, all 3 of our patients had recurrent glioblastoma. The development of recurrence with this tumor is associated with a poor prognosis with mean survival of 20-30 weeks with treatment (21). It is possible that their altered post-treatment anatomy and physiology made their blood brain barriers more permeable to ixazomib penetration. A newly diagnosed glioblastoma may be more resilient to treatment. We anticipate a future phase I analysis comparing ixazomib alone with ixazomib and a cytotoxic agent such as temozolomide.

In conclusion, orally administered ixazomib reaches brain tumor tissue. It reaches blood concentrations in human recurrent GBM patients similar to previously established pharmacokinetic profiles in mice and humans with multiple myeloma. Its therapeutic potential needs to be determined with further analysis.

\section{Acknowledgements}

Not applicable.

\section{Funding}

Clinical trial support was provided by Takeda, Inc.

\section{Availability of data and materials}

The datasets used and/or analyzed during the current study are available from the corresponding author on reasonable request.

\section{Authors' contributions}

JO designed the experiments. RP and JO implemented the experiments. JQ, EH, DA, GB, LG and JO analyzed and interpreted the data. JQ, RP, EH, DA, GB, LG and JO drafted and revised the manuscript. All authors read and approved the final manuscript.

\section{Ethics approval and consent to participate}

All procedures performed in studies involving human participants were in accordance with the ethical standards of the institutional and/or national research committee and with the 1964 Helsinki declaration and its later amendments or comparable ethical standards. Informed consent for collection of the data was obtained from all individual participants included in the study.

\section{Patient consent for publication}

Informed consent for publication of the results was obtained from all individual participants included in the present study.

\section{Competing interests}

JO receives research grant support and clinical trial support from Takeda, Inc. and the National Cancer Institute. JO serves on the editorial board of the American Cancer Society.

\section{References}

1. Porter KR, McCarthy BJ,Freels S, Kim Y and Davis FG: Prevalence estimates for primary brain tumors in the United States by age, gender, behavior, and histology. Neuro Oncol 12: 520-527, 2010.

2. Omuro A and DeAngelis LM: Glioblastoma and other malignant gliomas: A clinical review. JAMA 310: 1842-1850, 2013.

3. Voss $\mathrm{P}$ and Grune T: The nuclear proteasome and the degradation of oxidatively damaged proteins. Amino Acids 32: 527-534, 2007.

4. Bladé J, Cibeira MT and Rosiñol L: Bortezomib: A valuable new antineoplastic strategy in multiple myeloma. Acta Oncol 44: 440-448, 2005.

5. Adams J, Palombella VJ, Sausville EA, Johnson J, Destree A, Lazarus DD, Maas J,Pien CS, Prakash S and Elliott PJ: Proteasome inhibitors: A novel class of potent and effective antitumor agents. Cancer Res 59: 2615-22, 1999.

6. Yin D, Zhou H, Kumagai T, Liu G, Ong JM, Black KL and Koeffler HP: Proteasome inhibitor PS-341 causes cell growth arrest and apoptosis in human glioblastoma multiforme (GBM). Oncogene 24: 344-354, 2005.

7. Kubicek GJ, Werner-Wasik M, Machtay M, Mallon G, Myers T, Ramirez M, Andrews D, Curran WJ Jr and Dicker AP: Phase I trial using proteasome inhibitor bortezomib and concurrent temozolomide and radiotherapy for central nervous system malignancies. Int J Radiat Oncol Biol Phys 74: 433-439, 2009.

8. Kong XT, Nguyen NT, Choi YJ, Zhang G, Nguyen HN, Filka E, Green S, Yong WH, Liau LM, Green RM, et al: Phase 2 study of bortezomib combined with temozolomide and regional radiation therapy for upfront treatment of patients with newly diagnosed glioblastoma multiforme: Safety and efficacy assessment. Int J Radiat Oncol Biol Phys 100: 1195-1203, 2018.

9. Styczynski J, Olszewska-Slonina D, Kolodziej B, Napieraj M and Wysocki M: Activity of bortezomib in glioblastoma. Anticancer Res 26: 4499-4503, 2006.

10. Kumar SK, Berdeja JG, Niesvizky R, Lonial S, Laubach JP, Hamadani M, Stewart AK, Hari P, Roy V, Vescio R, et al: Safety and tolerability of ixazomib, an oral proteasome inhibitor, in combination with lenalidomide and dexamethasone in patients with previously untreated multiple myeloma: An open-label phase 1/2 study. Lancet Oncol 15: 1503-1512, 2014.

11. Kumar SK, Bensinger WI, Zimmerman TM, Reeder CB, Berenson JR, Berg D, Hui AM, Gupta N, Di Bacco A, Yu J, et al: Phase 1 study of weekly dosing with the investigational oral proteasome inhibitor ixazomib in relapsed/refractory multiple myeloma. Blood 124: 1047-1055, 2014.

12. Richardson PG, Baz R, Wang M, Jakubowiak AJ, Laubach JP, Harvey RD, Talpaz M, Berg D, Liu G, Yu J, et al: Phase 1 study of twice-weekly ixazomib, an oral proteasome inhibitor, in relapsed/refractory multiple myeloma patients. Blood 124: 1038-1046, 2014.

13. Kupperman E, Lee EC, Cao Y, Bannerman B, Fitzgerald M, Berger A, Yu J, Yang Y, Hales P, Bruzzese F, et al: Evaluation of the proteasome inhibitor MLN9708 in preclinical models of human cancer. Cancer Res 70: 1970-1980, 2010.

14. Chauhan D, Tian Z, Zhou B, Kuhn D, Orlowski R, Raje N, Richardson P and Anderson KC: In vitro and in vivo selective antitumor activity of a novel orally bioavailable proteasome inhibitor MLN9708 against multiple myeloma cells. Clin Cancer Res 17: 5311-5321, 2011. 
15. Gupta N, Diderichsen PM, Hanley MJ, Berg D, van de Velde H, Harvey RD and Venkatakrishnan K: Population pharmacokinetic analysis of ixazomib, an oral proteasome inhibitor, including data from the phase III TOURMALINE-MM1 study to inform labelling. Clin Pharmacokinet 6L 1355-1368, 2017.

16. Gentile M, Offidani M, Vigna E, Corvatta L, Recchia AG, Morabito L, Morabito F and Gentili S: Ixazomib for the treatment of multiple myeloma. Expert Opin Investig Drugs 24: $1287-1298,2015$

17. Gupta N, Zhao Y, Hui AM, Esseltine DL and Venkatakrishnan K: Switching from body surface area-based to fixed dosing for the investigational proteasome inhibitor ixazomib: A population pharmacokinetic analysis. Br J Clin Pharmacol 79: 789-800, 2015.

18. Kummar S, Rubinstein L, Kinders R, Parchment RE, Gutierrez ME, Murgo AJ, Ji J, Mroczkowski B, Pickeral OK, Simpson M, et al: Phase 0 clinical trials: Conceptions and misconceptions. Cancer J 14: 133-137, 2008.
19. Burger PC, Heinz ER, Shibata T and Kleihues P: Topographic anatomy and CT correlations in the untreated glioblastoma multiforme. J Neurosurg 68: 698-704, 1988.

20. Louis DN, Ohgaki H, Wiestler OD and Cavenee WK (eds.): WHO Classification of Tumours of the Central Nervous System. (Revised 4th edition), IARC, Lyon, 2016.

21. Wu W, Lamborn KR, Buckner JC, Novotny PJ, Chang SM, O'Fallon JR, Jaeckle KA and Prados MD: Joint NCCTG and NABTC prognostic factors analysis for high-grade recurrent glioma. Neuro Oncol 12: 164-172, 2010. 